\title{
EL MODELO TEXTUAL DE BASILEA Y EN EFECTO
}

\author{
Pura Guil Povedano \\ Universidad Complutense de Madrid
}

\begin{abstract}
Resumen: El objetivo de este trabajo es presentar un análisis de en efecto, adoptando un modelo textual (Modelo de Basilea) elaborado fundamentalmente a partir de la lengua italiana. El análisis parte de asumir la hipótesis de que el valor informativo asociado con una dada expresión lingüística juega un papel fundamental en la determinación de su función, alcance y relieve. Igualmente se tratará de poner de manifiesto la problemática que genera el no coincidente uso de la puntuación en italiano y español, por lo que a los marcadores discursivos se refiere.
\end{abstract}

Palabras clave: en efecto, Modelo textual de Basilea, nivel informativo, puntuación, coma.

Abstract: This paper's goal is to offer an analysis of the Spanish item en efecto using a text model (Basel Model) that has been elaborated mainly on the basis of Italian language's data. The analysis is based on assuming the hypothesis that the information value associated with a given linguistic expression plays a critical role in determining its function, scope and relief. Also the paper will seek to highlight the problems generated by the mismatched punctuation in Italian and Spanish, in terms of discursive markers.

Keywords: en efecto, Textual Basel Model, information level, punctuation, comma.

\section{INTRODUCCIÓN}

Probablemente, cuando estas páginas vean la luz, ya se habrá publicado la traducción y adaptación al español que he hecho del libro L'interfaccia linguatesto. Natura e funzioni dell'articolazione informativa dell'enunciato (Ferrari et al. 2008) ${ }^{1}$, en el que se presenta la versión más perfilada y completa hasta el momento del modelo textual elaborado por el llamado Grupo de Basilea (Proietti 2008), que desde un enfoque modular está orientado fundamentalmente al análisis de los textos escritos funcionales (no literarios) italianos contemporáneos. Más

${ }^{1}$ Una reseña del libro puede encontrarse en Guil 2009. 
exactamente se trata de la versión española de las partes Primera y Segunda ${ }^{2}$, las más teóricas, aquellas en las que se describen los fundamentos del modelo textual, cuya elaboración corrió a cargo de Angela Ferrari, salvo dos epígrafes, obra de Anna Maria De Cesare, y un epígrafe de Luca Cignetti. La Tercera parte del libro original recogía una serie de trabajos, en los que se aplicaba el modelo al análisis de diversos aspectos, sintácticos y léxicos, de la lengua italiana. Estos trabajos estaban elaborados por los tres autores citados y por otros investigadores del Grupo de Basilea (Letizia Lala, Claudia Ricci, Carlo Enrico Roggia y Magda Mandelli). En la versión española, se ha sustituido esta Tercera parte 3 por un capítulo de aplicación del modelo a varios fenómenos del español, realizado por Margarita Borreguero Zuloaga ${ }^{4}$.

La reflexión que, a partir básicamente de la lengua italiana, ha ido desarrollando a lo largo de los años Angela Ferrari, ha tenido como resultado la elaboración, junto con su equipo de investigación, de un modelo de unidades discursivas que representa un enorme esfuerzo de sistematización de los aspectos más candentes que se plantea la lingüística textual de hoy día. Así, convencida de la rentabilidad analítica que posee este modelo, he querido, con la traducción y adaptación de la obra, contribuir a difundirlo en ámbito hispánico. Buena muestra de su aplicabilidad son los más de 260 ejemplos de textos reales españoles, tomados del Corpus de Referencia del Español Actual, (CREA), de los que me he servido a lo largo de la traducción para ilustrar los múltiples fenómenos analizados de acuerdo con el modelo, que figuran en el original italiano y que encuentran así correspondencia en español, debiendo tenerse en cuenta, además, que se trata de fenómenos muy variados y relacionados con las dimensiones lógicoargumentativa, tópica e informativa de la organización textual.

Al objeto de poner de manifiesto la capacidad del modelo de Basilea de constituirse en instrumento analítico, eficaz y eficiente, capaz de aportar, desde una perspectiva textual, nuevos datos que contribuyan a un enriquecimiento de las descripciones de ciertos fenómenos lingüísticos ofrecidas desde otros enfoques, me propongo analizar aquí el marcador discursivo español en efecto, sin dejar de echar una mirada a su equivalente italiano más cercano, in effetti. Y ello al amparo de una de las hipótesis teóricas fundamentales del modelo: el nivel denominado jerárquico-informativo cumple el papel de interfaz entre el valor semántico básico de las formas lingüísticas y el nivel de la organización textual. Igualmente, trataré de poner de manifiesto la problemática que genera

2 Denominadas «La lengua, el texto, la interfaz lengua-texto» $\mathrm{y}$ «La organización informativa del Enunciado y la organización semántico-pragmática del texto», respectivamente.

3 «Dos aspectos lingüísticos de la organización informativo-textual: el focalizador incluso y las posiciones periféricas del Enunciado».

${ }^{4}$ Ferrari, Angela / Borreguero Zuloaga, Margarita: La interfaz lengua-texto. Un modelo de estructura informativa, traducción y adaptación al español de P. Guil. Madrid, Biblioteca Nueva, en prensa. 
el no coincidente uso de la puntuación en italiano y español, ciñéndome a la relativa a los marcadores.

\section{EL MODELO DE BASILEA Y LOS MARCADORES DISCURSIVOS ${ }^{5}$}

\subsection{Rasgos pertinentes del modelo}

Dentro de este marco teórico, la Unidad Textual ${ }^{7}$ básica es la Unidad Comunicativa, que cuando está determinada lingüísticamente (es decir, cuando es explícita y no implícita) está representada por el Enunciado, que constituye así la manifestación lingüística de un acto de composición textual, marcado ilocutivamente. Las Unidades Comunicativas se distribuyen a lo largo del texto en un espacio semántico-pragmático tridimensional en el que se reconocen un plano principal y un plano secundario (o más de uno), que configura el trasfondo del plano principal.

El Enunciado está formado por material semántico, tanto denotativo como instruccional. Este material, por el hecho de estar implicado en una operación de naturaleza comunicativa, posee una organización "informativa", en la que se pueden distinguir varios niveles de carácter modular, de los que aquí nos interesa señalar dos: el nivel de la articulación Tópico-Comentario, estructurado sobre la relación de respectividad (aboutness) que rige entre un referente textual y la correspondiente predicación semántica; y el nivel jerárquico-informativo, que articula el Enunciado en tres tipos de espacios o Unidades Informativas, jerárquicamente ordenadas y provistas cada una de ellas de una propia especificidad funcional, informativa y textual. Se trata de las siguientes Unidades Informativas:

a) el Núcleo, necesario y suficiente para formar el Enunciado, del que ocupa el primer plano; define «la función ilocutiva -el tipo de acción comunicativa que motiva la totalidad del acto de enunciación- y la función textual de todo el Enunciado, es decir, el tipo de acción a través de la cual participa en la composición del texto» (Ferrari / Borreguero en prensa: I.4.2.1) y, bajo ciertas circunstancias, puede estar coordinado;

b) el Marco, que abre el Enunciado y precede al Núcleo, del que define su pertinencia semántica, ilocutiva y textual; es una Unidad facultativa y susceptible de coordinación textual;

c) el Apéndice, es también una Unidad facultativa; situada en el segundo plano del Enunciado, depende de un Núcleo, un Marco u otro Apéndice, Unidades

5 Utilizaré aquí "marcador discursivo" en un sentido amplio, para remitir a los operadores, conectores o marcadores discursivos stricto sensu.

${ }^{6}$ Me limitaré a señalar solo los aspectos del modelo que resultan indispensables para que se pueda entender el análisis efectuado.

7 Se distinguen los términos técnicos del modelo mediante el uso de la mayúscula inicial. 
a las que sigue o en las que se inserta, y a las que elabora por subordinación, precisando su interpretación semántica, ilocutiva o textual; puede reiterarse.

Respecto al contenido de estas Unidades no hay restricciones, solo inciden exigencias de tipo comunicativo: dicho contenido debe poder actuar como soporte de la función informativo-textual que las define. Lo que significa que, en principio, un mismo material lingüístico puede ocupar cualquiera de las tres Unidades y desempeñar las funciones informativas correspondientes. $\mathrm{Y}$ ello, tanto en el caso de que se trate de constituyentes denotativos como instruccionales.

Es oportuno también señalar -sobre todo teniendo en cuenta el tipo de análisis que presentaré más adelante- que entre las secuencias de unidades de significado que integran el texto se da, entre otros, un tipo de relaciones que define su dimensión lógica, como pueden ser la "concesión", la "sucesión temporal", "la reformulación", etc.

\subsection{Las funciones informativas de los marcadores discursivos}

Dentro de este marco teórico, se ha prestado una particular atención a los marcadores discursivos, tanto en perspectiva monolingüe como contrastiva, ya que en su funcionamiento parece ponerse claramente de manifiesto el papel de intermediación que desempeña la estructura jerárquico-informativa entre la lengua y el texto ${ }^{8}$.

Por regla general, los marcadores disfrutan de una gran movilidad posicional: no es difícil que un mismo marcador pueda aparecer en posición inicial, intermedia o final del Enunciado. Dada su movilidad, los marcadores pueden ocupar cualquiera de las tres Unidades Informativas del Enunciado -Núcleo, Marco y Apéndice- y adquirir así las funciones informativas correspondientes.

Que existe una relación entre la posición ocupada por los marcadores y su interpretación, parece ser generalmente aceptado por los estudiosos. Ahora bien, lo que el modelo de Basilea sostiene es que la distribución en el texto genera en la interpretación de los marcadores tres tipos de efectos:

a) el primer efecto atañe a su valor lógico-semántico, más específicamente, al valor de empleo y matices de sentido asociados a su significado de base;

b) el segundo efecto concierne al alcance del marcador, es decir, la extensión de los constituyentes que caen bajo su dominio;

c) el tercer efecto recae sobre el relieve atribuido a la relación expresada por la semántica del marcador en la arquitectura semántico-pragmática global del texto.

${ }^{8}$ Me refiero a estudios como los siguientes: Ferrari 2003, 2005, 2008, 2014; Ferrari / Mandelli 2007; Ferrari / Ricci 2011; De Cesare 2006, 2010; De Cesare / Borreguero 2014; Ricci 2008a, 2008b; Mandelli 2004, 2006, 2008; Borreguero 2014, Borreguero / López Serena 2011; Guil 2014. 
Así pues, en elámbito de este modelo, se ha propiciado la reflexión «sull'influsso generale che un dato tipo di posizione sintattica e un dato profilo prosodico o interpuntivo esercitano sul valore semantico-lessicale» de los marcadores (Ferrari 2014: 129)

Hasta aquí, he tratado de describir a grandes rasgos las líneas básicas del Modelo de Basilea, como marco teórico del análisis y descripción del funcionamiento textual del marcador en efecto, que presentaré más adelante, y que se propone, además, ilustrar el modo en el que se produce la intermediación de la estructura jerárquico-informativa del texto. Pero, es conveniente realizar antes algunas consideraciones sobre la cuestión de la puntuación en italiano y español.

\section{A PROPÓSITO DE LA PUNTUACIÓN}

La puntuación constituye un nivel de organización lingüística que, dentro del modelo que nos ocupa, asume una gran importancia, ya que se entiende que, por estar codificados en él valores textuales, ofrece instrucciones interpretativas sobre las unidades constitutivas del texto. Limitándonos a la coma, cuando no es requerida «ni por la norma sintáctica — como cuando, por ejemplo, separa dos elementos coordinados por asíndeton-, ni por la semántica, para desambiguar, ni por la pragmática, para ayudar en la interpretación de estructuras excesivamente pesadas y complejas, entonces existen buenas posibilidades de que su presencia deba entenderse en sentido informativo» (Ferrari / Borreguero §1.4.1.2). La coma puede aparecer dentro de una Unidad Informativa o marcar una frontera informativa entre Unidades. Aunque también puede estar ausente a la hora de delimitar Unidades Informativas, lo que es más bien raro tratándose de contenidos denotativos, pero no lo es tanto respecto a los instruccionales, al menos en italiano.

Con referencia a la lengua italiana escrita, se ha advertido que la puntuación no tiene una repercusión interpretativa sistemática en el caso de los marcadores. La presencia de puntuación es, en general, suficientemente indicativa de la existencia de una frontera informativa. Así, por ejemplo, si el marcador está situado al inicio del Enunciado, seguido de una coma, se podrá interpretar que está ocupando una unidad de Marco; si, en cambio, ocupa una posición dentro del Núcleo del Enunciado y está flanqueado por comas, constituirá seguramente una Unidad Informativa autónoma de Apéndice. Ahora bien, la ausencia de comas no puede interpretarse automáticamente como ausencia de articulación informativa, esto es, como integración del conector en la Unidad Informativa que lo alberga: un conector que inaugura un Enunciado puede ser identificado como Marco, sin necesidad de estar seguido de una coma. La cuestión resultará más compleja de determinar si el conector está en inserción en el Enunciado, sin marca de puntuación alguna. Habrá de ser evaluada caso por caso: dependerá 
del cotexto, de la estructura sintáctica de la que forma parte o de la entonación de lectura proyectada por el Enunciado que lo acoge.

Por tanto, al menos por lo que se refiere a los marcadores, en italiano, la presencia de puntuación puede ser determinante de la interpretación que se haga, pero la ausencia de puntuación no es decisiva de la lectura que se efectúe ${ }^{9}$. En cambio, en español, nos enfrentamos a una problemática diferente, ya que el dilema lo provoca no tanto la ausencia, como en italiano, sino la presencia de las comas, que, a mi juicio, puede no responder a un valor informativo-textual, sino estar simplemente determinada por una norma de uso.

Debe recordarse que italiano y español asumen posturas diversas respecto a la puntuación. En italiano la puntuación tiene un carácter más facultativo, pues «in Italia, diversamente dalla Spagna, non si può parlare di norme emanate da un ente guida ufficiale come la Real Academia Española» (Carrera Díaz 2011: 398), sobre todo teniendo en cuenta que las normas lingüísticas dictadas por entidades como la Real Academia Española y la Asociación de Academias de la Lengua Española «hanno potere normativo per gli ispanofoni» (Carrera Díaz 2008: 297). Y así, centrándonos en el caso de los marcadores discursivos, la Ortografía de la Lengua Española (2010), en su descripción de los usos normativos de la coma, apunta que los conectores van seguidos o enmarcados por comas. Y señala:

Frente a las conjunciones, los conectores no suelen formar un grupo sintáctico con el segmento que los sigue. Precisamente esta independencia sintáctica favorece la libertad posicional de la que muchos de ellos gozan, y determina que, por lo general, se aíslen mediante signos de puntuación del resto del enunciado. En la cadena hablada, los conectores discursivos se caracterizan asimismo por su independencia fónica, de manera que suelen formar grupo entonativo propio (2010: 3.4.2.2.5., p. 343).

Ahora bien, un poco más adelante, en el mismo parágrafo, y de nuevo parangonándolos con las conjunciones, ya no se modalizan las aseveraciones como aquí («suelen», «por lo general», «suelen»,...), sino que, contraponiéndolos a las conjunciones, se afirma sin reserva que «Los conectores, en cambio, aparecen aislados en la cadena escrita y en la oral» (2010: 3.4.2.2.5., p. 344).

Originariamente la puntuación nace para satisfacer la necesidad de reproducir por escrito las características prosódicas del discurso oral. En la Ortografía de 2010, sin embargo, se adopta ya un enfoque lógico-sintáctico y, distanciándose de la tradicional vinculación entre puntuación y prosodia, se señala que aunque son a menudo sistemas paralelos «no puede decirse que uno refleje el otro» (2010: 288). Y en este sentido se advierte igualmente que si bien las unidades entonativas pueden coincidir con las unidades sintácticas, no lo

${ }^{9}$ Mayor detalle puede encontrarse en los trabajos citados supra, en nota 8, especialmente en Ferrari 2014 y Ricci 2008b. 
hacen necesariamente, y, en ese caso, «el uso de los signos de puntuación debe plasmar la organización de estas últimas» (2010: 288). Ahora bien, no obstante lo anterior, la cuestión es que la regla de puntuación de los conectores de 2010 es básicamente la misma que la que figuraba en la Ortografía de 1999, en la que se mantenía que con la puntuación «se pretende reproducir la entonación de la lengua oral» (1999: 55). Esta fuerte vinculación entre oralidad y escritura, así como el valor preceptivo de las normas, parece prevalecer todavía en el uso de la puntuación ${ }^{10}$. Es cierto, sin embargo, que cabe también la opción de no puntuar, pero según los datos que he recogido (v. infra) la presencia de la coma en los textos escritos españoles es cuatro veces superior a su ausencia (v. también infra para datos relativos al italiano). Y, lo que es más importante para el caso que nos ocupa, cuando se puntúa, la regla académica relativa a los conectores (o «enlaces», como se denominaban en la edición de 1999) se generaliza en su aplicación y los textos escritos tienden a mostrar un uso indiscriminado de ella, sin atender a posibles distinciones entre elementos o entre los diferentes usos de un mismo elemento.

En los estudios sobre marcadores resulta también generalizada la idea de que constituyen una unidad propia ya sea tonal ya sea sintácticamente, lo que determina que aparezcan en la escritura entre signos de puntuación. Aunque también es cierto que no dejan de hacerse salvedades al respecto.

Así, por ejemplo, Martín-Zorraquino / Portolés (1999: 4064-4065) dicen que se encuentran limitados como incisos ${ }^{11}$ por una entonación peculiar que, aunque no es enfática, en la lengua escrita «se refleja habitualmente situando el marcador entre comas, aunque no sea extraño que en ocasiones no se escriba ningún signo de puntuación», ofreciendo ejemplos de escritores de reconocida fama, como el peruano J. R. Ribeyro y los españoles F. Lázaro Carreter, L. Goytisolo y F. Savater.

Por su parte, Montolío (2001) distingue dos tipos de enlaces, según vayan o no entre pausas y/o signos de puntuación, que denomina «parentéticos» e «integrados», respectivamente, presentando estos últimos un elemento subordinante en su formación (dado que, aunque, en vista de). En este último grupo estarían incluidas también las conjunciones. Ahora bien, en un trabajo posterior, en el que analiza varios enlaces de tipo parentético, observa que «en ocasiones aparecen entre comas en los ejemplos procedentes de corpus de lengua escrita, si bien la puntuación resulta ciertamente muy fluctuante». (Montolío 2006: 83).

10 Sin embargo, estudiosos de ortografía advierten de que no debe entenderse que «toda coma representa una pausa», ni que «en ausencia de coma no existe pausa» (Martínez de Sousa 2014: 309-310).

11 Recuérdese que en otro tiempo la coma era denominada también "inciso" (Carrera Díaz 2008 y 2011). 
Bustos (2013: 101-102) relativiza su posición y subraya la complejidad del problema, aduciendo varias razones relacionadas, a su juicio, con la pausa y los conectores: su ausencia cuando el enlace lo realiza una conjunción o locución conjuntiva; o el hecho de que, cuanto menos gramaticalizado esté el enlace, la presencia de la coma resulta potestativa; y viceversa, a mayor grado de gramaticalización, la aparición de la coma será más habitual y esperable. Aporta, asimismo, datos referidos al recuento efectuado en un corpus textual sobre una treintena de enlaces situados en posición inicial de enunciado: solo media docena de ellos van seguidos de coma en el 100\% de las ocurrencias, en tanto que los otros enlaces presentan un porcentaje de uso de la coma que va del $95 \%$ al $6 \%$. La fluctuación es considerable, desde luego, teniendo en cuenta, además, que Bustos solo ha examinado la posición inicial de enunciado, que es, sin embargo, la posición que encontramos en los textos más comúnmente seguida de coma.

Una ojeada a los estudios específicos dedicados a los marcadores desde un punto de vista prosódico, pone de manifiesto las diferentes realizaciones prosódicas que presentan entre sí e incluso la diversidad de comportamiento que un mismo marcador puede adoptar en razón de las funciones que desempeñe. Hay muchos casos en los que no se observa un contorno entonacional independiente y, en cuanto al entorno prosódico del marcador, no siempre hay frontera y cuando la hay puede estar indicada bien por pausa, bien por un reajuste tonal, tendiendo el linde melódico previo a aparecer con más frecuencia que el final (Hidalgo 2010; Martín Butragueño 2003).

Así pues, dada la diversidad de comportamiento prosódico de los marcadores, no parece consistente la generalización que los presenta como dando lugar sistemáticamente a un grupo entonativo propio -emparejado con un grupo sintáctico autónomo-, enmarcado por pausas que, en la lengua escrita, se representan por comas.

\section{IN EFFETTI}

En un trabajo de 2006, pero publicado en 2008, Magda Mandelli describe el comportamiento textual de esta locución, adoptando para ello el enfoque del modelo de Basilea, según la versión elaborada hasta ese momento ${ }^{12}$. Se sirve de datos pertenecientes tanto al italiano escrito como al oral.

Distingue la estudiosa, en primer lugar, un uso adverbial de in effetti, que se sitúa junto al verbo, operando sobre el predicado. Tendencialmente está integrado en el Enunciado, es decir, no se aprecian cortes prosódicos o de puntuación que lo sigan o lo precedan. Desde el punto de vista semántico, se pueden advertir

12 Y así, por ejemplo, la autora hace uso de una Unidad de "Incipit", que más tarde se reelaboraría dando lugar a la de Marco que es la que forma parte de la versión actual del modelo, y que es la que utilizaré en la descripción de su trabajo. 
dos matices de significado, uno que apela a "lo efectivo" y otro que subraya el carácter verdadero del Enunciado. He aquí un par de sus ejemplos:

(1) Se i nostri esempi non fossero scanditi da due unità tonali, come abbiamo anticipato, ma da un'unica unità tonale di tipo assertivo, come quella delle frasi nominali proposta da Benveniste, la struttura sintattica di tali esempi sarebbe diversa da quella che in effetti è. (LISULB_DID_MANU_Gramm) (Tomado de Mandelli 2008: 441).

(2) [...] Il lettore con competenza semantica dell'italiano può verificare che è quanto succede in effetti [...] (LISULB_SAG_LIN) (Tomado de Mandelli 2008: 441).

Cuando, en cambio, la locución funciona como marcador, tiene siempre un significado básico confirmativo. En razón de su distribución, según Mandelli, asume tendencialmente dos valores.

En primer lugar, puede aparecer en posición inicial del Enunciado, a veces seguido de una coma -en la lengua escrita- o de una cesura entonativa -en la lengua oral-, ocupando la Unidad de Marco; pero también puede aparecer integrado sintáctica y entonativamente ${ }^{13}$ en el Núcleo del Enunciado. En ambos casos tiende a expresar una relación explicativa (de motivación). Véanse dos de los ejemplos propuestos por Mandelli:

(3) Telecom Italia aveva già sostituito il risponditore automático con la risponditrice automatica, "perché più rispondente ai gusti dell'utenza". Lo avrebbe sottoscritto anche Totò: la serva serve, e la risponditrice è più rispondente. In effetti la voce artificiale al femminile è gentile ed efficiente: guida con sicurezza chi chiama il 12 pregandolo di recitare nomi, cognomi, comuni, vie, strate e piazze (LISULB_GIO_S24H_contr) (Tomado de Mandelli 2008: 442).

(4) Dal punto di vista della composizione del testo, alla precedente concezione 'architettonica', cioè ad un tempo spaziale e statica, si può utilmente per gli scopi didattici affiancare una concezione egualmente spaziale ma questa volta dinamica. Il testo in costruzione può in effetti venire concettualizzato come uno spazio metaforico di operazioni mentali (e concrete: il produrre periodi), come uno 'spazio d'azione' o 'di azioni' in cui chi scrive è libero di agire a sua guisa, libero di 'muoversi' in diverse direzioni (LISULB_SAG_LIN) (Tomado de Mandelli 2008: 442).

En segundo lugar, puede encontrarse en posición intermedia del Enunciado, sin estar integrado en él, es decir, enmarcado por dos comas o cesuras entonativas; o bien, estar situado en posición final del Enunciado, tras coma o cesura

${ }^{13}$ El término utilizado por los miembros del Grupo de Basilea es «linearizzato», que contraponen a «non integrato». 
entonativa ${ }^{14}$. En los dos casos ocupa la Unidad de Apéndice y, según Mandelli, favorece una interpretación reformulativa, que ilustra mediante ejemplos como los siguientes:

(5) [...] il parlato-parlato si presenta ad una analisi lingüística come frammentato, ridotto, segmentato, tuttavia tale frammentazione è solo apparente. A parte le interruzioni e i frequenti cambi di programma, che, in effetti, frammentano il parlato, la apparente frammentazione dipende dal fatto [...] (LISULB_SAG_LIN) (Tomado de Mandelli 2008: 443).

(6) *DOM: ecco // quindi da zero a tre // il minimo / proprio // cioè/ proprio / lei / dovesse decidere di investire i [//] nell'azionario / nel breve / non vorrebbe andare oltre il tre / in effetti // giusto ? (C-ORAL-ROM: Gestione patrimoniale)

Estos valores de empleo de in effetti, tienen asociados, de acuerdo con el modelo, una serie de efectos en cuanto a sus correspondientes alcance y relieve.

\section{EN EFECTO}

\subsection{Estudios sobre en efecto}

Trataré de resumir a continuación, muy brevemente, las principales características atribuidas a en efecto por los estudios que he podido consultar.

La Nueva Gramática de la Lengua Española (RAE 2009: §3011o) considera que se trata de una locución adverbial que -junto con otras locuciones adverbiales y adverbios, como efectivamente- incluye en la clase de los adverbios del enunciado, de tipo evidencial, entre aquellos que intensifican la fuerza de lo que se asevera. Señala igualmente que casi todos los adverbios evidenciales pueden usarse para responder preguntas ( $\$ 30.11 \mathrm{p})$. Sin embargo, no aparece en la clasificación semántica que presenta de las locuciones adverbiales usadas como conectores discursivos ( $\$ 30.13 \mathrm{a})$.

Al revisar la bibliografía consultada ${ }^{15}$, que emplea enfoques teóricos diversos, y bien sea considerado marcador, operador o conector, de naturaleza modal o no, puede decirse que, en términos generales, se atribuye a en efecto un significado confirmativo, si bien hay quien estima que se trata de un efecto de sentido contextualmente generado (Solis 2012). A partir de este significado confirmativo se apunta su carácter polifónico (Falk 2006, Fuentes 2009, Llopis en prensa). En cuanto a las funciones discursivas que puede desempeñar, se señala la de

14 En los corpus utilizados por Mandelli, este uso en posición final aparece «quasi únicamente nella comunicazione parlata» (Mandelli 2008: $n$. 11).

15 Portolés 1998, Martín Zorraquino / Portolés 1999, Santos 2003, Flores 2003, Fernández Loya 2004, Falk 2006, Fuentes 2009, Solís 2012, García Negroni / Sawerwein 2014, Llopis (en prensa). 
«operador de refuerzo argumentativo» (Portolés 1998); la de «marcador de modalidad epistémica» (Martín-Zorraquino / Portolés 1999, Flores 2003) que se relaciona con la de reformulación (Martín-Zorraquino / Portolés 1999, Falk 2006) o directamente es considerado un marcador reformulativo-confirmativo (García Negroni / Sawerwein 2014). Santos (2003) estima que en efecto es una «locución reactiva de confirmación». Para Fuentes (2009) se trata de un operador modal, con el uso de modalizador de confirmación de un contenido previo, dicho o presupuesto, indicando además que «cuando confirma la tesis avanzada por el propio locutor, va seguida de un argumento que la justifica», lo que es propio de textos argumentativos o demostrativos. Flores (2003) además de la antes señalada función de marcador de modalidad epistémica, le asigna también la de marcador ilocutivo de confirmación. Llopis (en prensa) distingue cuatro funciones de en efecto: «marcador discursivo de modalidad epistémica de confirmación», «marcador discursivo conector argumentativo de confirmación», «marcador discursivo conector de reformulación explicativa» y «operador modal que remite a la realidad». Esta última función guarda relación con el sentido de en efecto que apuntan como similar a realmente Fuentes (2009), Santos (2003) y Falk (2006) y como no confirmativo Solis (2012). Recogeré, por último, la indicación formulada por diversos autores señalando que el empleo predominante de en efecto se da en textos escritos de registro formal: Fuentes (2009), Martín-Zorraquino / Portolés 1999, Fernandez Loya (2004)16.

\subsection{Corpus utilizado y algunos recuentos}

Para extraer los datos empleados en el análisis, he utilizado el Corpus de Referencia del Español Actual (CREA) de la Real Academia Española (RAE) ${ }^{17}$. He consultado la base de datos completa, sin restricción temporal, pero con referencia solo a España, y con el criterio selectivo: Libros, Tema: "Ciencias sociales". No obstante he hecho un pequeño sondeo para determinar la frecuencia de aparición del marcador en este y otros subcorpus del CREA, que arroja los datos, en valores totales y relativos, recogidos en la siguiente tabla. La consulta de "En efecto", esto es, con mayúscula inicial, es indicativa de que encabeza el Enunciado, tras un punto. En cambio, la consulta de "en efecto", con minúscula inicial, no es tan esclarecedora: puede tratarse tanto de la locución adverbial como del marcador, pudiendo ocupar la posición interior o final de Enunciado, o bien el inicio del Enunciado tras un signo de puntuación fuerte distinto al punto, como pueden ser, por ejemplo, el punto y coma o los dos puntos.

${ }^{16}$ Que lo contrapone así a infatti.

17 Accesible en línea: http://corpus.rae.es/creanet.html 


\begin{tabular}{|l|l|lr|lr|lr|rr|}
\hline & \multicolumn{2}{|l|l|l|l|l|l|}{$\begin{array}{l}\text { Todos los medios } \\
\text { y temas }\end{array}$} & \multicolumn{2}{|l|}{$\begin{array}{l}\text { Medio: Textos } \\
\text { orales }\end{array}$} & \multicolumn{2}{|l|}{$\begin{array}{l}\text { Medio: Libros } \\
\text { Ciencias sociales }\end{array}$} & \multicolumn{2}{l|}{$\begin{array}{l}\text { Medio: Libros Ciencias } \\
\text { y tecnología }\end{array}$} & Medio: Periódicos \\
\hline En efecto & 2.562 & 10 & $0,39 \%$ & 316 & $12,33 \%$ & 289 & $11,28 \%$ & 529 & $20,65 \%$ \\
\hline en efecto & 2.570 & 56 & $2,18 \%$ & 310 & $12,06 \%$ & 96 & $3,74 \%$ & 676 & $26,30 \%$ \\
\hline
\end{tabular}

Si bien es cierto que los textos escritos que integran la base de datos constituyen un $90 \%$ de la misma, en tanto que los orales solo representan un $10 \%$, cabe, a mi juicio, entender, a la vista de los datos numéricos obtenidos, que la frecuencia de uso de en efecto en textos orales es muy inferior a la que presenta en textos escritos. Lo que parece confirmar las apreciaciones en este sentido que, como hemos visto, han formulado diversos estudiosos ${ }^{18}$.

\subsection{ANÁLISIS DE EN EFECTO}

\subsubsection{Locución adverbial evidencial}

5.3.1.1. Con esta función de locución adverbial evidencial su presencia es bastante escasa en el corpus ${ }^{19}$. A parece siempre integrada en el Enunciado, junto al verbo e incidiendo sobre el predicado verbal. Dada su integración, puede incluso constituir el Foco final (end-Focus) del Enunciado, función de la que están excluidos los marcadores:

(7) El aval más sólido a la teoría del recelo de Franco hacia Carrero Blanco lo aportó la hija del general durante una reunión en la que estuvieron presentes algunos ex ministros de la dictadura. La duquesa les dijo que Carrero se había comprometido con el príncipe de España a abandonar la presidencia del Gobierno tan pronto como se produjera la muerte de su padre. Ella lo sabía porque el propio Carrero, arrepentido de su compromiso, acabó por confesarlo al cabo de algunos meses. Utrera Molina fue testigo de la confidencia de la duquesa de Franco $[\ldots]$.

Lucubraciones políticas al margen, una cosa es cierta: el pacto entre Carrero y el príncipe existió en efecto. Lo confirma la lectura de un fragmento de la

${ }^{18}$ Apreciaciones que también me han servido de orientación en la elección del subcorpus del CREA. La magnitud y posible heterogeneidad de las ocurrencias registradas en el medio "periódicos", me han hecho inclinarme por el medio "libros", eligiendo el área temática Ciencias sociales, a la que se le puede atribuir, en principio, la característica de estar integrada por textos de tipo expositivo-explicativo y no solo argumentativo. No obstante, como se verá, algunos de los ejemplos que presento provienen de otros subcorpus cuando el fenómeno que pretendo ilustrar resulta más evidente que en las ocurrencias encontradas en el de Ciencias sociales.

${ }^{19}$ Bastante más recurrente en el corpus, como adverbio evidencial integrado en el Enunciado, es efectivamente: «Es preciso decir de inmediato que la democracia es un ideal o concepto límite de la organización social, no una fórmula política efectivamente existente aquí y ahora.» (CREA, Savater, F., Invitación a la ética, Barcelona, 1995). Una revisión del propio texto de la Nueva Gramática de la Lengua Española, Manual (RAE 2010), (versión digital), muestra un total de 7 ocurrencias de efectivamente, todas ellas en función de adverbio evidencial, con valor semántico de 'lo efectivo' y en ningún caso encuadradas por comas. 
conversación publicada entre don Juan Carlos y José Luis de Vilallonga en las páginas de El Rey [...]. (CREA, Herrero, L., El ocaso del régimen. Del asesinato de Carrero a la muerte de Franco, Madrid, 1995).

Esta locución adverbial, al estar integrada e incidir en el predicado verbal, forma parte de la Unidad Informativa que dicho predicado esté ocupando. Tiene valor denotativo, no textual, y refuerza la aserción. No confirma nada anteriormente dicho o implicado, sino que semánticamente apunta hacia 'lo efectivo', apareciendo típicamente en contextos que contraponen el mundo de las apariencias y el mundo de lo real:

(8) $[\ldots]$ el extraño artilugio especialmente diseñado para este menester era conocido como Borderó. Una vez preparado el rodaje del plano, los ensayos se hacían escuchándose el fragmento seleccionado; el actor vocalizaba la canción como si en efecto estuviera cantando. (CREA, Del Rey del Val, P., Montaje. Una profesión de cine, Barcelona, 2002).

(9) La pulsión agresiva que en el fondo deseo descargar, deseo a la vez haberla contenido, y de no serlo, como en efecto ocurre, muestro mi Yo débil y la depresión por la agresión verificada. (CREA, Castilla del Pino, C. Introducción a la psiquiatría, 1. Problemas generales. Psico(pato)logía, Madrid, 1993).

Aunque también, al reforzar el valor de verdad del Enunciado, lo presenta como verdadero, especialmente su predicado:

(10) El genio, afirma Schelling, actúa como la naturaleza en cuanto puede encerrar, en algún momento, en alguna obra, el sentimiento de lo infinito en una forma concreta y finita; como lo sublime en Kant, pues. Ahora bien, quien es capaz de comprender todo esto, quien es capaz de encerrar lo finito en lo infinito, es en efecto una especie de dios, de demonio o de héroe, valoración que desemboca o refuerza el aristocratismo metafísico de los genios románticos. (CREA, Ynduráin, D., Del clasicismo al 98, Madrid, 2000).

Pero, a pesar de su indiscutible integración sintáctica y, por tanto, entonativa en el Enunciado, no es difícil, sin embargo, encontrarla en el corpus enmarcada por comas, tanto orientada semánticamente hacia 'lo efectivo' (11), como hacia 'lo verdadero' (12). Obsérvese el efecto perturbador que, en mi opinión, provoca una lectura con solución de continuidad entonativa:

(11) Con el fin de iniciar la verificación de esta hipótesis -politización y despegue-, hemos desarrollado este ensayo de encuesta-piloto. Es decir, si, en efecto, hay un cambio de mentalidad, y si este cambio implica una tendencia autoritaria-conservadora o progresista-democrática. En todo caso, se trata sólo de abrir un camino sobre actitudes políticas y, de ningún modo, asentar conclusiones definitivas o generales; tiene, pues, sólo un carácter muy indicativo. (CREA, Morodo, R. Por una sociedad democrática y progresista, Madrid, 1982). 
(12) Cada vez decimos más "esto hay que hacerlo rápido" frente a la opción de las generaciones anteriores que expresaban "esto hay que hacerlo rápidamente" o bien "esto hay que hacerlo deprisa". Según la gramática normativa, las palabras adecuadas para esa idea son, en efecto, "rápidamente" o "deprisa", puesto que ambas complementan a un verbo (y para complementar a un verbo se necesita un adverbio) y no a un sustantivo (función que corresponde a los adjetivos). (CREA, Grijelmo, A., La seducción de las palabras, Madrid, 2001).

5.3.1.2. Esta locución adverbial puede aparecer aislada, usada reactivamente, como respuesta o réplica. Aparece así típicamente en diálogos, pero también en textos monológicos, bien por imitación de los dialógicos (13), bien por desdoblamiento polifónico (14), pero estableciendo siempre un vínculo anafórico con el texto previo, que permite interpretar la respuesta. ${ }^{20}$ Ocupa y satura la Unidad Informativa de Núcleo y, por tanto, cumple un acto ilocutivo, el de confirmación ${ }^{21}$ :

(13) -¿Qué ha hecho usted por París?

-Pues descansar, pasear...y he ido al Parlamento francés a ver cómo transcurrían las cosas.

-Ha querido usted recordar el pasado.

- // /En efecto. /Núcleo // Me ha ocurrido lo que a un cordobés amigo mío. [...]. (CREA, Fisas, C., Historias de la Historia, Barcelona, 1993).

(14) Salamanca. Altos del Palacio Episcopal-Cuartel General; bien significativa hibridación, la de este pasajero destino bélico del edificio. Pido audiencia a Serrano, y tengo que esperar largo rato en la antecámara. ¿A quién veo entrar en ella? ¿No es Millán Astray, con su inseparable asistente legionario? // / En efecto. /Núcleo // Millán se sienta, como yo, y en un rincón queda el asistente, portador de una voluminosa cartera de mano. (CREA, Laín Entralgo, P., Descargo de conciencia (1930-1960), Madrid, 1989).

5.3.1.3. También, como en el caso anterior, en usos dialógicos o monológicos, podemos encontrar la locución, pero esta vez ocupando la posición de Apéndice, como refuerzo de una respuesta afirmativa, por lo que el cumplimiento del acto ilocutivo no corresponde a en efecto, sino a la expresión afirmativa que ocupa el Núcleo al que se ancla el Apéndice:

(15) - Sí, así es. Conozco a Dreifuss desde hace muchos años, hemos trabajado juntos. Me preguntó si había posibilidades de indagar el asunto y le dije que si se enviaba una comisión rogatoria era posible. Al volver a leer los papeles de la

20 Tanto el empleo registrado en 5.3.1.2. como el de 5.3.1.3. no son indicados por Mandelli 2008 respecto al italiano, probablemente por olvido.

${ }^{21}$ Siguiendo las convenciones del modelo en relación con la lengua escrita, con la doble barra oblicua (//) indicaré los límites de Enunciado, mientras que la barra oblicua sencilla (/) servirá para indicar los de la Unidad Informativa, normalmente identificada en superíndice. Pero limitaré estas indicaciones a aquellos casos en que resulten necesarias para la comprensión del análisis. 
comisión anterior he visto que era confusa. Y los abogados del EBC pudieron evitar la entrega de la documentación.

- Hasta el nombre de la entidad estaba mal escrito...

- // / Sí, /Núcleo en efecto. /Apéndice // No se sabía bien si se trataba de EBC o de European Bank Corp. Había varias entidades que se llamaban igual. (CREA, El Pais, 27/06/1997).

\subsubsection{Marcador discursivo}

Cabe suponer que, a partir de su base léxica, fundamentada en la dicotomía 'apariencia' / 'realidad efectiva', 'verdad', se desarrolla el significado confirmativo ('conforme a la verdad, a la realidad'), como expresión de un compromiso explícito con el valor de verdad de la aserción que introducen, que adopta esta locución adverbial cuando es empleada como marcador discursivo -significado confirmativo que, con vinculación anafórica, ya habíamos visto aflorar en contextos dialógicos o similares, en los dos apartados anteriores-. El marcador en efecto va a mantener este significado de base confirmativo en todas sus funciones y posiciones discursivas.

\subsubsection{En posición inicial de Enunciado}

En posición inicial ocupa el marcador la Unidad Informativa de apertura típica del Enunciado, el Marco. Es en este emplazamiento, gracias a las características de dicho espacio informativo, donde se advierte con mayor claridad la semántica relacional de este tipo de elementos. Al ser el Marco el espacio que alberga la información respecto a la que el Núcleo adquiere su pertinencia textual, y al expresar un marcador un contenido relacional, se pone de manifiesto la pertinencia y coherencia de la relación que mantiene el Núcleo con el Enunciado o Enunciados previos del texto. Es como si se produjese una convergencia de funciones entre el Marco y el marcador que lo ocupa.

En todas las ocurrencias del corpus en las que ocupa en efecto el Marco, lo satura, esto es, no va acompañado de otro material lingüístico. Puede decirse que esta es la posición en la que es más frecuente la presencia de puntuación: además, naturalmente, del signo previo correspondiente, el marcador va seguido de puntuación -fundamentalmente una coma- en el 96,03\% de las ocurrencias 22 . Es fácil, pues, en estos casos identificar el marcador como Marco, dada su posición, pero también por la elevada presencia de puntuación corroborándolo.

22 En los cálculos se han tenido también en cuenta las ocurrencias que, en minúscula, aparecen en el corpus tras signo de puntuación fuerte, como dos puntos o punto y coma. Este 96,03\% lo alcanza en efecto en el subcorpus del CREA Ciencias sociales, pero con otros criterios (como Ciencias y tecnología) llega al 98,39\% de los casos. En el texto del Manual de la NGLE (RAE 2010), todas las ocurrencias de en efecto en inicio de Enunciado van seguidas de coma. 
Asume en efecto aquí, tendencialmente, un valor semántico-pragmático de tipo justificativo, o motivador: además de confirmarla, justifica o motiva la aserción anterior, introduciendo un (nuevo) argumento en su apoyo. Se trata de una relación lógica de dicto, ${ }^{23}$ es decir, una relación de composición textual que dota al texto de una particular arquitectura lógica: a una afirmación, hipótesis u opinión se le hace seguir una aserción que, además de informar, justifica su contenido. Como ocurre habitualmente, se aprovecha la posición de Marco para situar allí aquellos marcadores que vehiculan en el texto una relación "fuerte": la motivación es una relación de carácter lógico, que, participando en su progresión argumentativa, hace avanzar el texto. Si su relieve procede de este peso argumentativo que asume, su alcance está potenciado también por la posición de Marco ocupada. No solo establece la conexión con informaciones anteriores, como acabo de apuntar, sino que proyecta esa relación hacia el cotexto derecho: incide sobre el Núcleo de su Enunciado y puede permanecer siendo válida, salvo indicación contraria, en los Enunciados sucesivos. Obsérvese cómo, en los ejemplos siguientes, los efectos del alcance semántico-pragmático de en efecto, saltan, sin tenerlos en cuenta, los contenidos ubicados antes del Núcleo (en otros Marcos o Apéndices), inciden sobre el Núcleo y superan incluso los límites de su Enunciado: se podría decir que todos los elementos hasta el final del párrafo transcrito caen bajo la influencia del marcador:

(16) Entre ellas destaca preferentemente la obra de San Pablo, a quien se ha considerado como uno de los grandes exoteristas del Cristianismo. // / En efecto, $/$ Marco1 a partir de una enseñanza iniciática o esotérica, $/$ Marco2 que sin duda Pablo compartió en el seno de los misterios crísticos,/Apéndice su mensaje está abierto a todas las comunidades y hombres./Núcleo // Él convirtió el cristianismo en la religión universal que más tarde llegaría a ser, conservando un equilibrio entre el aspecto exterior y el interno, que constituye la apoyatura de su inmenso edificio teórico pero sin llegar a manifestarse bajo una forma esotérica. // (CREA, Garrido, C., El esoterismo. Claves de las doctrinas secretas, Barcelona, 1983).

(17) En principio, y en teoría, el Romanticismo se opone al Clasicismo, tanto a sus tratados como a los modelos ejemplares, a los cánones y, en definitiva, a la abstracción intemporal y universal de la imitatio, a los principios absolutos. No deja de ser paradójico que los teóricos de la filosofía romántica, al tiempo que niegan esos universales, construyan otros más absolutistas todavía. // / En efecto,/Marco1 para los pensadores románticos,/Marco2 existe un espíritu de los pueblos que se expresa en la lengua, el derecho y la literatura o el arte./Núcleo // Tal espíritu -se afirma- es intemporal, es una esencia que se mantiene igual a sí misma y se manifiesta bajo distintas formas y variaciones accidentales. // (CREA, Ynduráin, D., Del clasicismo al 98, Madrid, 2000).

${ }^{23}$ En cambio, las otras relaciones lógicas que también recorren un texto, las relaciones de re, «coinciden con las conexiones lógicas que rigen entre los eventos que constituyen el Mundo real o imaginario al que se refiere el texto» (Ferrari / Borreguero, en prensa, p. 169). 
El siguiente texto resulta interesante no solo por constituir, nuevamente, un ejemplo del amplio alcance del marcador hacia el cotexto derecho, sino porque la secuencia en estudio está introducida por dos puntos, como sucede con un número considerable de ocurrencias encontradas en el corpus. Como es sabido, los dos puntos tienen un carácter intrínsecamente textual, pues señalan que la segunda unidad está interpretativamente al servicio de la primera. Por tanto, el lector deberá tenerlo en cuenta para interpretar lo comunicado en primer lugar y decodificar así apropiadamente toda la secuencia (Lala 2004). Los dos puntos, junto con en efecto, introducen la relación lógica de motivación, sirviendo los dos puntos para subrayar y reforzar el valor del marcador:

(18) // No puede dejar de consignarse que Castilla se llega a independizar políticamente de León por la intervención de un monarca navarro y no por acciones internas. // Pero sólo habrá que esperar dos años para que Castilla y León vuelvan a depender de una única Corona: // en efecto, en 1037 muere Vermudo III rey de León y Fernando de Castilla, su cuñado, que ya se titulaba Rey, le sucede. // Al año siguiente Fernando I, Rey del recién nacido Reino de Castilla era ungido como Emperador Hispánico, es decir, de León. // (CREA, Alonso Fernández, J., La nueva situación regional, Madrid, 1990).

\subsubsection{En posición final de Enunciado}

En un muy reducido número de ocurrencias del corpus ocupa en efecto la posición final del Enunciado, correspondiente a la Unidad Informativa de Apéndice, a la que me referiré en el próximo apartado. Podría interpretarse que en efecto, en esta posición, constituye una especie de pensamiento a posteriori (afterthought), con la común orientación anafórica de este mecanismo. Pero obsérvese, además, en el texto de (19), que en efecto confirma, reformulándola, la tesis anterior, mientras que es en el siguiente Enunciado en el que se aportan nuevas evidencias. E1 Enunciado en el que está ubicado en efecto sirve, así, como una especie de enlace, al inicio de un nuevo párrafo, entre la tesis del Enunciado/ párrafo previo y la ilustración que se ofrece en el Enunciado siguiente:

(19) Lo curioso de la tesis de Alvin Toffler es que, a su vez ambas posturas ocasionan efectos psicológicos y políticos similares, puesto que conducen por igual a la paralización de la imaginación y de la voluntad. "Si la sociedad del mañana es, simplemente, una versión ampliada -como en cinerama- del presente, no necesitamos hacer gran cosa para prepararnos para ella. Si, por el contrario, la sociedad se halla inevitablemente abocada a la destrucción dentro del plazo de nuestras vidas, nada podemos hacer al respecto." El resultado, en ambos casos, sería la petrificación, la pasividad, el fatalismo depredador y suicida.

A simple vista, esta "paralización" se produce, en efecto. Entre los jóvenes, se maquilla de pasotismo; entre los mayores, de un pesimismo casi masoquista. (CREA, $A B C, 24 / 12 / 1983)$. 
5.3.2.3. En posición intermedia del Enunciado

Dentro del Enunciado, en efecto se registra enmarcado entre comas en el corpus (CREA, Ciencias sociales), en el 89,59\% de los casos ${ }^{24}$. La identificación del espacio informativo que ocupa no resulta inmediata: tanto la función de locución adverbial como la de marcador discursivo, ambas posibles en esta posición, presentan una gran oscilación en el uso de la puntuación, que no facilita su análisis.

\subsection{En la Unidad de Apéndice}

Una vez separadas las ocurrencias correspondientes al uso de en efecto como locución adverbial, la mayor parte de las remanentes permiten entender que corresponden a su empleo como marcador discursivo ubicado en un Apéndice. Se trata de una Unidad con estatus informativamente subordinado, lo que la sitúa en el trasfondo comunicativo del Enunciado. Esta subordinación informativa del Apéndice hace que habitualmente se sitúen en él aquellos marcadores que expresan relaciones también textualmente subordinadas, con un relieve bajo y un alcance estrictamente local. $Y$ eso es lo que sucede con en efecto: cuando está situado en posición de Apéndice parece favorecer una lectura de tipo reformulativo, o sea, una relación "débil", de dicto pero no lógico-argumentativa, sino discursiva, que no hace avanzar la argumentación sino que confirma, reiterándolo, un contenido ya previamente comunicado.

Aunque ciertamente predominan las ocurrencias enmarcadas entre comas, con solución de continuidad entonativa, como suele ser habitual en los Apéndices, no siempre ocurre así. Como puede comprobarse en (20), el Enunciado en el que está en efecto en inserción, reitera, confirmándolo, lo dicho anteriormente para, a continuación, mediante una puntuación que eficazmente la destaca, añadir una información nueva conclusiva en otro Enunciado. Las repeticiones léxicas confirman igualmente su valor reformulativo, a pesar de la ausencia de las comas:

(20) // Cuando Gramsci dijo que él no tenía la culpa de que la realidad de su tiempo fuera revolucionaria, dijo una gran verdad. // La culpa en efecto no la tenía él. // La tenía Mussolini. // (CREA, Duque, A. El suicidio de la modernidad. Una revisión crítica de la cultura contemporánea, Barcelona, 1984).

En (21) sucede algo similar, aunque esta vez en efecto aparece flanqueado por comas. En lugar de repetir un sintagma nominal («la culpa») como en (20),

${ }^{24}$ En CREA, Ciencias y tecnologia , aparece entre comas en el 82,19\% de las ocurrencias. En el texto del Manual de la NGLE (RAE 2010), va siempre entre comas cuando ocupa esta posición interna del Enunciado. 
aquí se aprovecha la naturaleza anafórica del encapsulador «la cuestión» para retomar el segmento anterior, reformulándolo. Obsérvese que la motivación o justificación de lo dicho previamente (E1), la aportan los tres últimos Enunciados (E3, E4 y E5), no el que alberga en efecto (E2), que se limita a cumplir un papel meramente discursivo, de anillo de enlace entre el primero y estos tres últimos Enunciados:

(21) // Y así se produjo, en noviembre de 1975, algo que dejó estupefactos a los estudiosos de la ciencia política en todo el mundo.// 1 / La cuestión,/

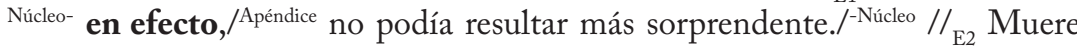
un dictador tras cuarenta años de régimen autárquico, después de haber sido el amigo y colaborador de Hitler y Mussolini. // ${ }_{\mathrm{E} 3}$ Deja ungido como Rey a un Príncipe que ha jurado los Principios y Leyes Fundamentales de la dictadura. // 4 Y en un país desarrollado como España, en las postrimerías del siglo xx, ese Príncipe accede al Trono sin que se produzca ni un conato en favor de la República. // E5 (CREA, Ansón, L.M., Don Juan, Barcelona, 1996).

Una estructura muy abundante en el corpus es la que presenta a en efecto insertado tras el Tópico del Enunciado (como también ocurre en (20) y (21)). $\mathrm{El}$ texto (22), aunque un tanto largo, tiene la ventaja de que permite ver con bastante claridad la forma de "trabajar" textualmente que tienen los Enunciados portadores de una reformulación, al menos aquellos con el marcador en efecto en Apéndice:

(22) También se separan los condados de Sobrarbre, Ribagorza y Pallárs de la Marca Tolosana. Esta independencia catalana, cuyos orígenes se desconocen, posibilitará el que varios condados se reúnan bajo la autoridad de Vifredo el Velloso, conde de Barcelona, que ostentará simultáneamente los títulos de conde y de "marchio" (marqués de la Marca).

Este proceso de desligamiento de las tierras españolas del poder carlovingio [...].

Por su lado, el condado de Aragón se integra totalmente en el círculo de los independientes Vascones pamploneses [...]

La total autonomía que van alcanzando los condados hispanos,[...]. No cabe duda de que, con condes de estirpe hispana, la percepción nacionalista y la búsqueda de la libertad de acción harían el resto. El gran sentido y capacidad del conde y marqués Vifredo el Velloso, bajo estos supuestos, le permitieron a finales del siglo Ix unificar bajo su mando, como se ha indicado, varios condados catalanes. El hecho es transcendente por cuanto supone el surgimiento de un nuevo Estado -el condado de Barcelona- que, al correr de los tiempos representará un papel protagonista en la Reconquista y conformará una de las regiones más netas y una Comunidad de acusadísima personalidad: Cataluña. Vifredo el Velloso, en efecto, conquista primero, y coloniza después, casi toda la "Cataluña Vieja". A las tierras reconquistadas y a sus condados propios 
de Barcelona y de Urgel suma, por herencia, los de Gerona y de CerdañaConfient. [...]. (CREA, Alonso Fernández, J., La nueva situación regional, Madrid, 1990).

La expresión referencial «Vifredo el Velloso» introduce esta entidad en el texto, en el Comentario del segundo Enunciado transcrito, en el que igualmente se suministran algunos de sus datos caracterizadores. Después el texto continúa desarrollándose siguiendo otros derroteros al menos durante tres párrafos, para retomar de nuevo esta entidad (ya como Tópico), con sus atributos identificadores, vinculándose explícitamente a la información ya dada («como se ha indicado»), en previsión de que pudiera haber pasado a un estado cognitivamente semiactivo. Tras un punto y aparte, ya en otro párrafo, nuevamente se menciona, también como Tópico, indicándose mediante en efecto en Apéndice que se confirma y reformula una información ya suministrada previamente en el texto, para a continuación seguir añadiendo, en los siguientes Enunciados, información nueva, que amplía y especifica la que se reformula en el Enunciado de en efecto. La reiteración de la entidad referencial y la reformulación expresada en el Enunciado y evidenciada por en efecto cohesiona y aporta coherencia al texto, sirviendo de apoyo a la continuidad tópica del mismo y activando informaciones tal vez semiactivas cognitivamente. Se trata claramente de actos de composición, de elaboración de la urdimbre del tejido textual, en los que el componente enunciativo prevalece sobre el lógico.

$\mathrm{Al}$ servicio igualmente de la vinculación con los segmentos previos del texto, pueden considerarse las estructuras introducidas por el verbo pronominal unipersonal tratarse de y en efecto en Apéndice, que con una cierta frecuencia se documentan en el corpus, máxime si, como en (23), aparecen en inicio de un nuevo párrafo. Este verbo tiene un claro valor anafórico, que se refuerza con en efecto en Apéndice y la reformulación a continuación de lo anteriormente dicho:

(23) Cuando regresé al despacho encontré una nota en la que me indicaban que me había llamado por teléfono un antiguo compañero de la Universidad. Como hacía un par de días me habían hecho una entrevista en televisión acerca de unos animales del zoo y varios compañeros y amigos me habían llamado por teléfono para hacer comentarios y felicitarme, pensé que se trataría de otro más. Así que no le devolví la llamada hasta última hora de la mañana.

Se trataba, en efecto, de un antiguo compañero de carrera al que no había vuelto a ver desde que terminamos los estudios. También me había visto por televisión y fue eso lo que le motivó para localizarme, según me contó posteriormente, pensando que yo podría ser su salvación. Necesitaba que el zoo le ayudase a resolver un problema que le había surgido. (CREA, López, M., Un gorila con paperas. Historias de un veterinario entre monos, Madrid, 2001).

Por último, quisiera señalar que, como antes adelanté, el alcance de la Unidad de Apéndice es muy limitado, estrictamente "local", en la construcción del 
significado semántico-pragmático del texto. Cuestión que resulta evidente en el ejemplo (24). En este texto se entrecruzan dos relaciones. La principal es una relación de motivación, así pues de tipo argumentativo, que conecta el Núcleo del E2 («ha sido un sobresaliente acierto ... de carácter profano o civil» con el Núcleo del E3 («pues es lo que menos se suele enseñar... platería religiosa»). En un segundo plano queda la relación subordinada vehiculada por «en efecto», que reformula, concretando, la aserción previa sobre el predominio de un determinado tipo de obras de arte, limitando su alcance a los Apéndices 1, 3 y 4 , es decir, a la sola relativa apositiva:

(24) // La ambición de la muestra no sólo descansa en el número de las piezas de metales preciosos reunidas para la ocasión, ni tampoco en el arco cronológico abarcado, que es prácticamente todo el periodo colonial, casi tres siglos, sino también en el esfuerzo para que hubiera representación en la misma de todos los centros o escuelas locales y, sobre todo, de la riquísima tipología de objetos.// ${ }_{\mathrm{E} 1}$ En este sentido,/Marco ha sido un sobresaliente acierto de la comisaria su empeño en que predominasen las obras de carácter profano o civil,/Núcleo que,/Apéndice1 en efecto, $/{ }^{/ \text {Apéndice2 }}$ son $97, /^{\text {Apéndice3 }}$ aproximadamente las dos terceras partes de lo exhibido,/Apéndices $/ /$ E2 /pues es lo que menos se suele enseñar en comparación de la mejor conocida platería religiosa./Núcleo // Eз. (CREA, El País, 08/05/1997).

\subsection{En la Unidad de Núcleo}

Es cierto que cuando se encuentra enmarcado por comas dentro del Enunciado, parece delinearse una tendencia a "extraer" informativamente el marcador, estableciendo un límite de Unidad Informativa, adscribiéndolo a la Unidad de Apéndice y atribuyéndole, en consecuencia, un valor de conexión "débil", discursiva, de tipo reformulativo. Pero no siempre ocurre así. Aparte los usos en calidad de locución adverbial (v. 5.3.1.1.), es posible identificar ciertos casos en los que, a pesar de la presencia de las comas, las condiciones sintácticas son netamente diversas de las que presentan las anteriores ocurrencias. Allí, parece prevalecer la inserción del marcador entre sujeto y predicado (v. 5.3.2.3.1), en cambio en las ocurrencias a las que me refiero ahora, en efecto está situado, en las oraciones predicativas, dentro del predicado, junto al verbo o el Foco, o en cualquier posición si la oración es presentativa. $Y$ en estos casos, a mi juicio, no obstante las comas, se ve favorecida la lectura "fuerte", es decir, en efecto presenta un valor lógico-argumentivo de tipo motivación, ejerce un amplio alcance y posee un relieve central en la progresión informativa del texto:

(25) En suma, para acceder a sus formas superiores, la vida hubo de adoptar un camino distinto del iniciado por los seres unicelulares. // La ampliación indefinida de éstos quedó, en efecto, interrumpida por limitaciones intrínsecas de la materia misma.// Ciertamente, un parameciollegó a ser considerablemente 
mayor y más inteligente que una bacteria; pero la capacidad de expansión de una gotita de protoplasma estaba limitada de antemano por problemas tan irresolubles como el de la tensión superficial.

En consecuencia, el camino a seguir fue el de la agrupación de células, y no el del aumento de tamaño de éstas. (CREA, Pinillos, J. L., Principios de psicología, Madrid, 1995).

(26) No es precisamente lo mismo que el animal tenga que aguardar el zarpazo de su enemigo para huir o defenderse, que aprenda a iniciar la huida o la defensa ante determinados estímulos-señal. Claro está que los instintos desempeñan a veces el mismo papel anticipatorio que los reflejos condicionados; // un olor, o cualquier otro estímulo distal, puede bastar en efecto para desencadenar una conducta evitativa o de otra índole. // Sólo que, como decimos, no habría lugar en el cerebro para prefijar todas las posibilidades señalizadoras que surgen en el decurso de la vida de un animal cualquiera; razón por la cual se explica acaso el hecho de que la inmensa mayoría de las llamadas conductas instintivas entrañan alguna componente adquirida, bien sea asociativa o no. (CREA, Pinillos, J. L., Principios de psicología, Madrid, 1995).

En (25) se confirma y motiva la aserción previa al Enunciado de en efecto, para seguir a continuación, con la misma orientación argumentativa, especificando esa motivación, hasta llegar a la relación de consecución (de dicto), basada en una consecuencia (de re), del Enunciado final. El mismo autor, en la misma obra, nos ofrece en (26) un uso de en efecto, también con valor de motivación de la aserción previa, pero esta vez sin comas, lo que resulta indicativo de la oscilación de uso señalada.

(27) Conforme la reforma política encuentra un rumbo menos vacilante, los partidos esgrimen ante ETA el considerable aval de sus votos y construyen paso a paso la certeza de encontrarse en un sistema democrático, pleno de legitimidad y abierto a la discrepancia. La respuesta terrorista ante esta situación de acorralamiento fue tratar de forzar la credibilidad y los límites de la reforma, provocando cada vez con mayor brutalidad al aparato militar y policial del Estado, a la espera de un "derechazo" desestabilizador de los más reaccionarios o, en su defecto, de una aceptable negociación. // El mantenimiento de la cadena de atentados a los que se une en Guernica el rechazo al Rey por los nacionalistas radicales de HB y las protestas por la muerte de un etarra en una dependencia policial culminarán, en efecto, en una intentona involucionista el 23 de febrero de 1981, con el Congreso de los diputados ocupado por un pelotón de guardias civiles. // Si bien no llegaron los golpistas a sustituir ni mucho menos el sistema democrático, como era su intención, suscitaron recelos contra la política autonómica en sectores del gobierno y los partidos de ámbito estatal; el complejo de democracia vigilada se volcó entonces en retardar las transferencias estatutarias. (CREA, García de Cortázar, F.; González Vesga, J. M., Breve historia de España, Madrid, 1994). 
Con el Enunciado de en efecto, en (27), se confirma y justifica la oportunidad del previo juicio de intenciones emitido, por lo que se refiere a una de las opciones de la alternativa planteada («un "derechazo" desestabilizador de los más reaccionarios»). El texto continúa después informando de las consecuencias derivadas de la «intentona involucionista».

Véanse seguidamente algunos ejemplos de en efecto en inserción en una construcción presentativa, esto es, aquella que no está articulada en torno a una entidad referencial, que funciona como Tópico, sobre la que incide una predicación:

(28)De donde resulta que el Pueblo de Dios no sólo reúne a personas de pueblos diversos, sino que en sí mismo está integrado por diversos órdenes.// Hay, en efecto, entre sus miembros una diversidad, sea en cuanto a los oficios, pues algunos desempeñan el ministerio sagrado en bien de sus hermanos, sea en razón de la condición y estado de vida, pues muchos en el estado religioso estimulan con su ejemplo a los hermanos al tender a la santidad por un camino más estrecho. // Además, dentro de la comunión eclesiástica, existen legítimamente Iglesias particulares, que gozan de tradiciones propias, permaneciendo inmutable el primado de la cátedra de Pedro, que preside la asamblea universal de la caridad, protege las diferencias legítimas y simultáneamente vela para que las divergencias sirvan a la unidad en vez de dañarla. // (CREA, VV.AA., Religión, Madrid, 1996)

La aserción del primer Enunciado de (28) se justifica en el Enunciado de en efecto y en el siguiente, unido por una relación lógica aditiva explícita («además»), pues ambos mantienen la misma relación de motivación con el primer Enunciado.

(29) El II Congreso del PDP comenzará mañana bajo el signo de lo electoral. Tiene esto importancia sustantiva. // No existen, en efecto, problemas pendientes como los que tenían los socialistas al iniciar su último Congreso. // No padece tampoco el PDP tensiones internas o corrientes como las presentadas por la democracia cristiana en Italia. // Lo que polariza el interés de este Congreso es algo que podría definirse como la adecuación instrumental del partido a una función muy concreta: la de oficiar como puente de enlace entre el centro y la derecha.// (CREA, $A B C, 25 / 01 / 1985)$.

La aserción "Tiene esto importancia sustantiva», de (29), se justifica por la exclusión de otras posibles razones en el Enunciado con en efecto y en el siguiente, coorientado argumentativamente, hasta llegar al último Enunciado, en el que se aduce el argumento positivo pertinente. En (30) se justifica la oportunidad del consejo previo, esgrimiendo la razón de prevención sanitaria que lo motiva: 
(30) Al comprar contenedores o vasos de plástico se debe preguntar si son adecuados para alimentos (ya que no existen tipos específicos producidos por industrias especializadas). // Existen, en efecto, en el comercio contenedores que pueden producir toxicidades, como las bolsas que dan al hacer la compra en supermercados, zapaterías, etcétera, que deben dedicarse exclusivamente al transporte de mercancías. // (CREA, Anónimo, Congelar en casa, Madrid, 1976).

Respecto a la lengua italiana, recuérdese que Magda Mandelli (2008) detectaba la presencia de in effetti, con valor lógico-argumentativo de tipo explicativo, en dos posiciones: en inicio de Enunciado, ocupando la posición de Marco, pero también en inserción en el Enunciado, dentro de la Unidad de Núcleo, aunque, eso sí, integrado en él sintáctica y entonativamente («linearizzato») (v. 4. supra). Por su parte, Angela Ferrari, en uno de sus últimos trabajos sobre dunque, señala respecto a la puntuación, «la realtà della scrittura italiana mostra che, benché esista l'alternativa presenza/assenza di virgole, la soluzione senza virgole è nettamente più rappresentata: delle 500 apparizioni di dunque inserito di cui mi sono occupata, solo 90 lo vedono infatti racchiuso tra virgole» (2014: 138). Lo que en términos relativos supone que un $82 \%$ de las ocurrencias de dunque en inserción aparecen sin comas: casi exactamente a la inversa de lo que, según mis cálculos, ocurre en el corpus español, donde en efecto en inserción aparece enmarcado por comas en el 89,59\% de las ocurrencias del subcorpus de Ciencias sociales, y en el 82,19\% de las del de Ciencias y Tecnología.

Una de las previsiones del modelo es que, como hemos ido viendo en las páginas anteriores, la asociación entre un marcador polifuncional y una Unidad Informativa de primer plano (como, por ejemplo, en inserción en el Núcleo, o en inicio absoluto de Enunciado, saturando un Marco) favorece una lectura "fuerte", lógico-argumentativa; en tanto que cuando el marcador está incluido en una Unidad Informativa de segundo plano (como, por ejemplo, el Apéndice) tiende a emerger un valor semántico-pragmático "débil". Ahora bien, señala igualmente Ferrari (2014: 146), que el valor fuerte del marcador insertado en un Núcleo se debilita si se enmarca entre comas, en el caso de Núcleos predicativos, pero no en el de Núcleos presentativos, lo que explica del siguiente modo: «se la connessione tra primo piano informativo e dinamismo logico-testuale del connettivo si trova ad essere affievolita quando dunque è racchiuso tra due virgole, è perché, se sintatticamente facoltativa, la coppia di virgole posta al centro dell'enunciato ha proprio l'effetto di creare uno sfondo informativo» ${ }^{25}$, mientras que la no incidencia de este mecanismo en el caso de las oraciones presentativas lo explica como consecuencia del «forte dinamismo comunicativotestuale iscritto nella funzione stessa di presentatività» (2014: 147). Pero no se olvide que estas observaciones están referidas directamente al italiano

${ }^{25}$ El resaltado en negrita es mío. 
escrito: si las comas no son necesarias para la indicación de un grupo sintáctico independiente, su presencia es de interpretar, naturalmente, como señal de la voluntad comunicativa del escritor, que desea situar en un segundo plano esa información, con las consecuencias que de ello se derivan.

Pero creo que el caso del español es distinto, y no solo por las opuestas cifras de uso referidas a la ausencia/presencia de la coma en las dos lenguas. Con una libertad mucho menor para usar la puntuación, con unas reglas ortográficas académicas con poder normativo, no parece arriesgado suponer que se haya producido un fenómeno de generalización o "sobreextensión" de una norma, la de situar entre comas a los marcadores en interior de Enunciado, que, sin embargo, no parece ser aplicable a todos y en todos sus usos. Contribuye igualmente a apoyar esta hipótesis tanto la oscilación que se registra en el uso de la coma en estos casos -aun por parte de prestigiosos escritores-, como la diversidad existente en la realización prosódica de los marcadores -incluso con casos de ausencia de frontera o realización no mediante pausa-, que permiten al menos poner en duda la consistencia de la norma en cuestión.

Por todo lo cual, mi propuesta consiste en considerar que cuando en efecto está situado cerca del verbo o del Foco en las construcciones predicativas, o en cualquier posición dentro de las presentativas, está ocupando la Unidad de Núcleo, lo que favorece una lectura fuerte de la conexión lógica que establece, de tipo explicativo o motivador, sin que la presencia de las comas tenga una consecuencia en la organización informativa del texto. Como tampoco la tiene en el caso de las presentativas italianas, aunque la explicación responda a una cuestión de dinamismo comunicativo-textual (Ferrari 2014: 147), y no a una homogeneización "abusiva" de empleos de la coma, como a mi juicio parece darse en español, al menos en el caso de las construcciones predicativas.

\section{CONSIDERACIONES FINALES}

En las páginas anteriores he presentado una descripción detallada del comportamiento discursivo de en efecto, con la finalidad de poner de manifiesto que utilizando un modelo de unidades textuales como el de Basilea se pueden obtener resultados más precisos que si solo se adopta un enfoque puramente sintáctico-semántico. Ha sido mi intención, además, reivindicar que, aunque este modelo estaba orientado inicialmente hacia la lengua italiana, resulta rentable también aplicado a otras lenguas, como el español.

Un rasgo de identidad del modelo es precisamente su asunción de la necesidad y conveniencia de tomar en consideración no solo el componente meramente gramatical, sino también aquel otro nivel de estructuración llamado jerárquicoinformativo, que funciona como interfaz entre las instrucciones suministradas por el nivel más básico de la organización de la lengua (gramática y léxico) y el nivel de la organización del discurso. Esto significa, fundamentalmente, que las funciones textuales de cualquier elemento lingüístico (denotativo o 
instruccional) dependen, por una parte, de su estatus informativo y, por otra, de las instrucciones codificadas a un nivel gramatical y semántico.

Desde este enfoque, las regularidades detectadas al analizar las ocurrencias de en efecto en el corpus nos han mostrado que puede funcionar como locución adverbial o como marcador discursivo. Además de modificar el predicado verbal en el que está integrada, la locución adverbial puede actuar también como elemento confirmativo si está saturando la Unidad de Núcleo y como refuerzo de una afirmación si ocupa la de Apéndice.

Cuando se utiliza como marcador discursivo, su valor semántico básico es confirmativo y en razón de la posición informativa que ocupe se determinan su valor de empleo, su alcance y su relieve.

Si se encuentra saturando un Marco o bien integrado en un Núcleo (v. infra), tiende a establecer una relación lógico-argumentativa de motivación, con un amplio alcance y alto relieve en la arquitectura semántico-pragmática del texto, dada su contribución al progreso de la línea argumentativa central del texto. En cambio, cuando ocupa la Unidad de Apéndice, ya sea en posición intermedia o final del Enunciado, favorece una lectura reformulativa, de tipo discursivo, con alcance limitado y bajo relieve, en correspondencia con su labor de mera (re-) elaboración textual.

Considerar integradas y no parentéticas, atribuyéndoles un valor fuerte, lógico-argumentativo de motivación, las ocurrencias de en efecto registradas en el predicado verbal de los Núcleos predicativos o en posición intermedia de los Núcleos presentativos, constituye una propuesta interpretativa, fundamentada en la organización semántico-pragmática a que dichas ocurrencias dan lugar. De las dos manifestaciones lingüísticas que inciden básicamente en la organización informativa del Enunciado, la sintaxis y la puntuación, esta propuesta otorga así un mayor peso a la sintaxis, al menos en estos casos, por considerar, entre otras razones antes apuntadas, que en español se ha producido una sobreextensión de la norma académica que regula la puntuación. Propuesta que, como es natural, deberá ser revalidada por sucesivas investigaciones sobre el comportamiento de otros marcadores discursivos en español y/o por la determinación de otros criterios distintivos pertinentes.

Por último, quisiera indicar que el aparente paralelismo que presentan la descripción de in effetti y la de en efecto, necesita también nuevas investigaciones que establezcan la tipología de textos y registros en los que prevalece su uso. 


\section{BIBLIOGRAFÍA}

Borreguero Zuloaga, A., "Left-periphery in discourse: Frame Units and discourse markers”, en A. Dufter - A. Octavio de Toledo (eds.), Left-peripheries in Spanish. Diachronic, typological and variationalist approaches, Amsterdam, John Benjamins, 2014, pp. 345-382.

Borreguero Zuloaga, A. - López Serena, A., "Marcadores discursivos, valores semánticos y articulación informativa del texto: el peligro del enfoque lexicocentrista", en H. Aschenberg - O. Loureda (eds.), Marcadores del discurso: de la descripción a la definición, Frankfurt, Iberoamericana Vervuert, 2011, pp. 169-210.

Bustos Gisbert,J.M.,Arquitextura:fundamentos del texto escrito en español, Universidad de Salamanca, Ediciones Univ. Salamanca, 2013.

Carrera Díaz, M., "La punteggiatura nelle lingue iberiche", en B. Mortara Garavell (ed.), Storia della punteggiatura in Europa, Bari, Laterza, 2008, pp. 297-338.

Carrera Díaz, M., "La punteggiatura in spagnolo e in italiano: storia, norma e tradizione", Studi italiani di linguistica teorica e applicata, en M. Borreguero - L. Luque (eds.), número temático, Linguistica italiana in Spagna, linguistica spagnola in Italia, XI, 3 (2011) pp. 381-401.

De Cesare, A. M., "Soprattutto tra avverbio focalizzante e congiunzione testuale", en E. Corino et al. (eds.), Proceedings XII EURALEX International Congress (Torino, 6-9.9.2006), II, Alessandria, Edizioni dell’Orso, 2006, pp. 1129-1135.

De Cesare, A. M., "Gli impieghi di ecco nel parlato conversazionale e nello scritto giornalistico", en A. Ferrari - A.M. De Cesare (eds.), Il parlato nella scrittura italiana odierna: riflessioni in prospettiva testuale, Bern, Lang, 2010, pp. 105-147.

De Cesare, A.M. - Borreguero, M., "The contribution of the Basel Model to the description of the polifunctionality of discourse markers: It. anche, Fr. aussi, Sp. también", en S. Pons Bordería (ed.), Models of discourse segmentation. Explorations across Romance Languages, Amsterdam, John Benjamins, 2014, pp. 55-94.

FALK, J., "En efecto es su cumpleaños mañana'. Observaciones sobre el marcador del discurso en efecto", en J. Falk - J. Gille - F. Wachtmeister Bermúdez, Discurso, interacción e identidad. Homenaje a Lars Fant, Stockholm, Stockholm University, 2006. pp. 37-63. Consultable en: http://www.diva-portal.org/smash/get/ diva2:711543/FULLTEXT01.pdf

Fernández Loya, C., "La traducción y el análisis contrastivo de los marcadores del discurso. Los casos de infatti y en efecto", AISPI. Actas XXII (2004), pp. 99113. Consultable en: http://www.contrastiva.it/baul_contrastivo/dati/sanvicente/ contrastiva/Marcadores/Fernández\%20Loya,\%20marcador\%20infatti.pdf

Ferrari, A., Le ragioni del testo. Aspetti sintattici e interpuntivi dell' italiano contemporaneo, Firenze, Accademia della Crusca, 2003.

Ferrari, A., "Connettivi e struttura del testo. Oltre la semantica lessicale”, en I. Korzen (ed.), Lingua, cultura e intercultura: l'italiano e le altre lingue (= Copenhagen Studies in Language, 31), Copenhagen, Samfundslitteratur Press, 2005, pp. 191-204.

Ferrari, A., "Congiunzioni frasali, congiunzioni testuali e preposizioni: stessa logica, diversa testualita”, en E. Cresti (ed.), Prospettive nello studio del lessico italiano, Atti 
del LX Congresso della Società Internazionale di Linguistica e Filologia Italiana, SILFI, (Firenze, 14-17.6.2006), Firenze, Firenze University Press, 2008, pp. 411-417.

Ferrari, A., "Connettivi e gerarchie testuali tra morfologia, sintassi e punteggiatura. Note a partire dall'italiano", en M. Borreguero - S. Gómez-Jordana (eds.), Marqueurs du discours dans les langues romanes, Limoges, Lambert-Lucas, 2014, pp. 129-148.

Ferrari, A. - Mandelli, M., "Note sull'impiego dei connettivi nei notiziari accademici del corpus Athenaeum", en M. Barbera et al. (eds.), Corpora e linguistica in rete, Perugia, Guerra, 2007, pp. 183-198.

Ferrari, A. et al., L'interfaccia lingua-testo, Alessandria, Edizioni dell'Orso, 2008.

Ferrari, A. - Ricci, C., "Valeur d'emploi, portée, relief. Observations descriptives et explicatives sur la relation entre position et inteprétation des connecteurs", en SHancil (ed.), Le role de l'Affect dans les marqueurs discursifs, Rennes, Publications de l'Université de Rouen et du Havre (PURH), 2011, pp. 41-62.

Ferrari, A. - Borreguero Zuloaga, M., La interfaz lengua-texto. Un modelo de estructura informativa, traducción y adaptación al español de P. Guil. Madrid, Biblioteca Nueva, en prensa.

Flores Acuña, E., Los marcadores de reformulación: análisis aplicado a la traducción español/italiano de en fin $y$ de hecho, Tesis Doctoral, Universidad de Málaga, 2003. (Consultable en http://www.contrastiva.it/baul_contrastivo/dati/barbero/Flores\%20 Acu\%C3\%B1a_tesis\%20doctoral.pdf)

Fuentes Rodríguez, C., Diccionario de conectores y operadores del español, Madrid, Arco Libros, 2009.

García Negroni, M.M.- Sawerwein Spinola, S., "La reformulation et le discours scientifique en espagnol et en français: à propos des instructions sémanticopragmatiques de en efecto et de en effeet', en M. Borreguero - S. Gómez-Jordana (eds.), Marqueurs du discours dans les langues romanes, Limoges, Lambert-Lucas, 2014, pp. 67-80.

Guil, P., Reseña a Angela Ferrari et al., L'interfaccia lingua-testo. Natura e funzioni dell'articolazione informativa dell'enunciato, Alessandria, Edizioni dell'Orso, 2008, 407 pp., en Cuadernos de Filología Italiana,16 (2009) pp. 313-359.

GuIL, P.,"La interfaz lengua-texto: observaciones contrastivas", comunicación presentada en Convegno Internazionale di Studi, Linguistica Testuale. Teorie, metodi, fenomeni, strutture. Linguistique Textuelle. Théories, méthodes, phénomenès, structures. Lingüistica Textual. Teorías, métodos, fenómenos, estructuras, Universität Basel, 2-4 luglio 2014.

Hidalgo, A., "Los marcadores y su significante: en torno a la interfaz marcadoresprosodia”, en O. Loureda - E. Acín - N. Vázquez (eds.), La investigación sobre marcadores del discurso en español, hoy, Madrid, Arco/Libros, 2010, pp. 61-92.

LalA, L., "I Due punti e l'organizzazione logico-argomentativa del testo", en A. Ferrari, (ed.), La lingua nel testo, il testo nella lingua, Torino, Istituto dell'Atlante Linguistico Italiano, 2004, pp. 143-164.

LLopis, A., "Entre la modalidad y la conexión: la confirmación. El caso de en efecto", RILCE Revista de Filología Hispánica, en prensa.

Mandelli, M., "Coordinazione frasale e coodinazioni testuali: il caso della congiunzione $e$ ", en A. Ferrari (ed.), La lingua nel testo, il testo nella lingua, Torino, Istituto dell'Atlante Linguistico Italiano, 2004, pp. 117-143. 
Mandelli, M., "Quella $e$ a inizio di frase...: scarti prosodici e interpuntivi tra elementi coordinati», en A. Ferrari (ed.), Parole frasi testi, tra scritto e parlato (= Cenobio LV/3), 2006, pp. 231-240.

Mandelli, M., "In effetti nel testo", en E. Cresti (ed.), Prospettive nello studio del lessico italiano, Atti del IX Congresso della Società Internazionale di Linguistica e Filologia Italiana, SILFI, (Firenze, 14-17.6.2006), Firenze, Firenze University Press, 2008, pp. 439-444.

Martín Butragueño, P., "Hacia una descripción prosódica de los marcadores discursivos. Datos del español de México", en P. Martín Butragueño - E. Herrera (eds), La tonía, dimensiones fonéticas y fonológicas, México, $P A G$, Colegio de México, 2003, pp. 375-402.

Martín Zorraquino, M.A. - Portolés, J., "Los marcadores del discurso", en I. Bosque - V. Demonte, Gramática descriptiva de la Lengua Española, Madrid, Espasa Calpe, 1999, pp. 4051-4213.

Martín Zorraquino, M. A.- Montolío, E., (coords), Los marcadores del discurso. Teoría y análisis, Madrid, Arco/Libros, 1988.

Martínez de Sousa, J., Ortografía y ortotipografía del español actual, Gijón, Eds. Trea, 2014.

Montolío, E., Conectores de la lengua escrita, Barcelona, Ariel, 2010 [2001].

Montolío, E.,"Por ahora/de momento/por el momento, es un tipo encantador. Operadores de debilitamiento argumentativo de origen temporal", en J. Falk - J. Gille - F. Wachtmeister Bermúdez, Discurso, interacción e identidad. Homenaje a Lars Fant, Stockholm, Stockholm University, 2006, pp. 81-107. Consultable en: http://www. diva-portal.org/smash/get/diva2:711543/FULLTEXT01.pdf

Portolés, J., Marcadores del discurso, Barcelona, Ariel, 1998.

Proietti, D., "Un modello di testualità e la scrittura "funzionale" / "comunicativa" nell'italiano contemporaneo", Rid. IT, Rivista on-line di Italianistica, 4 (2008), pp. 173-186.

Real Academia Española, Ortografía de la Lengua Española, edición revisada por las Academias de la Lengua Española, Madrid, Espasa, 1999.

Real Academia Española y Asociación de Academias de la Lengua Española, Diccionario panbispánico de dudas, Madrid, Santillana, 2005.

Real Academia Española y Asociación de Academias de la Lengua Española, Ortografía de la lengua española, Madrid, Espasa, 2010.

Real Academia Española y Asociación de Academias de la Lengua Española, Nueva gramática de la lengua española, Madrid, Espasa, 2009.

Real Academia Española y Asociación de Academias de la Lengua Española, Nueva gramática de la lengua española, Manual, versión digital, Madrid, Espasa, 2010.

Ricci, C., "Impiego frasale e testuale dell'avverbio effettivamente", en E. Cresti (ed.), Prospettive nello studio del lessico italiano, Atti del IX Congresso della Società Internazionale di Linguistica e Filologia Italiana, SILFI, (Firenze, 14-17.6.2006), Firenze, Firenze University Press, 2008a, pp. 455-460.

Ricci, C., "I connettivi nel testo", en A. Ferrari et al., L'interfaccia lingua-testo. Natura e funzioni dell'articolazione informativa dell'enunciato, Alessandria, Edizioni dell'Orso, 2008b, pp. 362-387. 
Santos Río, L., Diccionario de partículas, Salamanca, Luso-Española de Ediciones, 2003.

Solis García, I., "Instrucciones procedimentales de los marcadores evidenciales en efecto y efectivamente", Pragmalingüistica, 20 (2012), pp. 239-254. 